
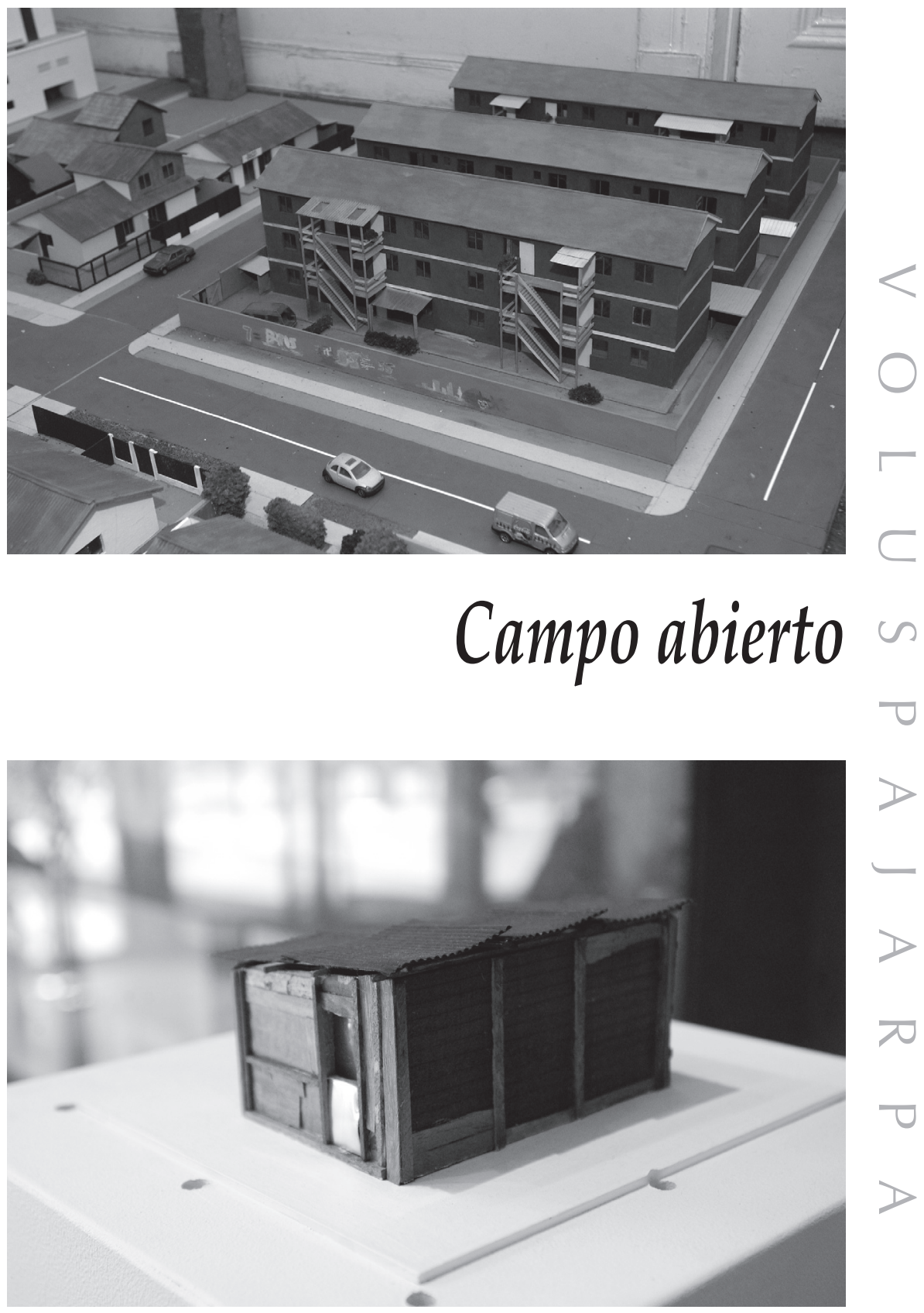

Frontal / Exposición Colectiva

Dimensiones Variables compuesta de: Maqueta al muro de $2.70 \times 3.70 \mathrm{~m}$.

Maqueta de mediagua sobre plinto $1.20 \mathrm{~m} \mathrm{X} 0.40 \mathrm{~m}$ X $0.40 \mathrm{~m}$

Dispositivo sonoro dentro de plinto.

Octubre de 2004- Fundación Bank Boston, Santiago 


\section{Los límites materiales: cuerpo y ceniza en La polca de los osos de Margo Glantz}

\section{Eugenia Brito}

Este brillante y complejo libro de ensayos de la gran escritora mexicana Margo Glantz se estructura en tres grandes hilos discursivos, el primero de ellos encierra la pregunta por un secreto: ¿de dónde viene el discurso? El segundo, titulado, "Los caminos de la memoria," transcurre provocando conexiones entre procesos de vida de escritores como Proust y Flaubert con los significantes escriturales de su obra. En el último, "La tumba sin sosiego," examina las relaciones entre el exterminio judío durante la ocupación nazi y la relación de Lévi y Celan entre otros, con sus producciones y su historia.

Partiendo de la premisa de que la escritura pone en escena un cuerpo y de que este cuerpo es a menudo un lugar con zonas ocultas y muchas veces bordeando lo indecible, Margo Glantz abre la relación entre la palabra, el silencio, el erotismo y la muerte. La relación entre erotismo y consagración del cuerpo genera una zona sagrada, que requiere de un instrumental preciso para su ejercicio, puesto que "el objetivo fundamental del erotismo es llegar a lo íntimo del ser, tocar lo más íntimo del ser, tocar el lugar mismo en que el ser desfallece. El paso del estado normal al del deseo erótico supone la relativa disolución del ser constituido en el orden de la discontinuidad(...). La escenografía erótica se basa en el principio de la destrucción de la estructura cerrada que en la vida normal tiene el compañero en el juego erótico.

La acción decisiva es la desnudez. Esta se opone al estado cerrado, es decir, al estado de existencia discontinua." ${ }^{1}$

La cita es de Bataille, uno de los autores más amados por Glantz en su construcción de este primer discurso. La Historia del Ojo, Mi madre, y otras producciones del gran escritor son citadas profusamente en este ensayo, ya sea para examinar su propia producción o bien, como en el caso de otras producciones, como La Casa de las bellas durmientes de Yasunari Kawabata, sirve para 
plantear el abismo entre horror y placer, existente entre el cuerpo de Eguchi, quien, ya en sus años finales, se prepara para el placer, con una joven desnuda y drogada. La muerte de la mujer es la cifra cúlmine de un progresivo descubrimiento que a partir de la piel y la respiración de los olores y sensaciones que emanan de las muchachas hacen conducir la memoria erótica y vital de Eguchi, el personaje que inicia un viaje final: el viaje último de toda vida: la muerte.

El miedo (el deseo) del incesto salvaguarda la prohibición del contacto: Eguchi no puede tocar a las jóvenes, así como ya casi no puede tocar los signos de la realidad que se sella para él con signos ya escritos y que debe revivir y tal vez reaprender en todas las magnitudes olvidadas o presentidas en sueños, pues yacen intuidas de manera fugaz y fragmentaria, y por lo tanto, se abren en sus revisiones en nuevas corporalidades, en otras disímiles corporalidades. Así, Eguchi llega a saber que la primera mujer de su vida fue su madre. Lo sabe gracias a que toca el seno de una de las dos jóvenes acostadas junto a él y ese saber lo traspasa, justo en el momento en que recuerda la muerte de su madre, poco antes de ver que a su lado una de las chicas está también muerta, probablemente de una sobredosis.

Ese saber, el placer de ese saber, mezcla de horror y de culpa, de apertura de un conocimiento culpable y perverso, abyecto, es uno de los puntos de apoyo con que Glantz elabora una propuesta de lectura, que, claro, se desliza con otras más, y que es como su corriente interna, o motor secreto: consiste en que todo libro se refiere al cuerpo, y con él a la sexualidad, a la historia de esa sexualidad, escondida o desplegada entre sus texturas, y las más de las veces esas texturas ocultan o reposan sobre un sexo de mujer. Prohibido o aclamado, ese sexo da vida al erotismo y a la pornografía, la que siempre contiene ese cuerpo femenino, a ratos la Medusa, una diosa oscura de efecto letal y paralizante; en otras, una infinita productora de conocimiento y de fecundidad, una Atenea, la diosa más respetada de los griegos.

Es allí donde se afirma la poética de Bataille, continúa Glantz, quien privilegia el exceso por sobre la continencia, la semejanza entre lo animal y lo humano -la desmesura- por sobre el ideal platónico de la belleza, lo bajo, lo considerado bajo por sobre lo alto, lo material sobre lo ideal, lo monstruoso, lo informe y lo escatológico por sobre lo armónico; la burla irrisoria sobre el saber institucional, siempre reverencial y referencial, como lo ha dicho Barthes. 
El erotismo como utopía requiere de lugares escondidos, ese primer escondite ha sido el del nombre, la primera máscara, a veces deseada literalmente como otro cuerpo que propone una nueva historia, otras veces, exigida para desviar el ojo de la censura, así lo ha hecho Bataille al publicar la Historia del Ojo; así lo han hecho autores en todo tiempo, y aquí Glantz anuda a su hipótesis la idea de que el cuerpo que encierra el relato ha pasado por viajes, mutaciones, por narraciones que se conmutan por partes del cuerpo, el ojo por un texto, la voz por la inscripción en la escritura, es decir, es la lengua la se conserva a precio de sangre. Parte del secreto, a veces ni tan secreto, polifonía del discurso que a ratos enseña y ensaya su génesis, en otras, la oculta, la convierte en su señuelo, su seducción impresa en una caótica materialidad. En el caso de Las Mil y Una Noches, Scherezade, sabe que el relato equivale a una noche más, a un hijo y que enmudecer es la muerte, el fin del proceso; entonces cada relato es su anillo de desposada y la continuación de la vida, por ello sus personajes tienen narraciones enmarcadas en su propia sangre.

El mito de Scherezade se vuelve a reimprimir en la historia de manera feroz; Sade encerrado casi toda su vida por hablar de la genitalidad, por elaborar un discurso racional si eso es posible sobre la sexualidad y el placer, no sobre el deseo, sobre la sexualidad y el crimen que muchas veces la regula dentro de las capas aristocráticas europeas. Passolini puso las 120 Jornadas de Sodo$m a$, como nombres del fascismo, un relato cinematográfico que le costó la vida. La censura, el encierro, precave: no se puede dentro del fascismo, ni dentro de las políticas autoritarias, revelar sus maquinarias de horror y de muerte. Confesarlo, testimoniarlo, hacer de ello arte, no mercancía, sino una estética dura y opaca, exige pagar un costo ante cualquier tiranía, y ese costo se paga en sangre, de ese pago da cuenta la inscripción incesante en la lengua del relato, es su política de sobrevivencia, su ornamentación y su trágico escenario. El testimonio, la política del testimonio transmutada en los cuerpos, en la sexualidad y en la política impresa en la sexualidad implica que el testigo a veces pierde su vida por ello, como ocurrió con Passolini.

Quisiera agregar que el texto de Glantz toma la forma de esa narración laberíntica de Scherezade: desde un relato se parte hacia otro en una sucesión de viajes, envíos, citas, estaciones, pago de peajes, puentes y reenvíos para llegar desde la mutación de piel 
al último tramo del cuerpo, a su radiografía dolorosa: el hueso. Auschwitz.

En "Los caminos de la memoria," capítulo situado entre sus dos jornadas, la del erotismo y el lugar femenino del discurso y el de la tumba sin sosiego de Primo Levi y Celan, se encuentran Rimbaud, el gran poeta del S. XIX, el que enunciará que el yo es otro. Para Glantz, sin embargo, de acuerdo a Mallarmé, Rimbaud no llega a lograr en su poesía ese camino, ese cambio. Sino más bien siguió el sendero imperialista francés: fue hacia el Otro cuando se dirigió a África, a las colonias dominadas por los franceses, allí es donde va a parar el poeta como traficante, uno de los oficios posibles auspiciados por el imperialismo francés. Paradojalmente allí donde espera hacer un corte vital, en realidad, lo que hace es una enfermedad, que lo lleva al corte de una pierna, y con ello al desenlace trágico y temprano, de retorno al centro de su historia. En otra dirección, Flaubert, en La Educación Sentimental, hace la exégesis de la historia de Francia previa a la instalación de Bonaparte en Europa y revisa la historia de su tiempo mientras formula su poética inscribiendo la palabra en el filo del pensamiento. Entonces analiza su historia, sus contextos culturales; con saña, observa la modernidad apareciendo como un decorado evanescente, metaforizado por su amada, Mme Arnoux, quien como los trajes que vistiera con profusión, envejece y de toda su pompa, sólo queda su cabellera blanca.

El recuerdo en Proust lo es de las mil impresiones que el tiempo desgasta, y que el sabor de la magdalena hace revivir, así Proust intenta para Glantz dar vida a todos los libros, la multiplicidad de libros que existen en uno sólo como virtualidades, desarrollos, escenas fugaces, desenlaces inéditos, giros inesperados. Como aquel de las criadas, una de ellas, Francoise, matando ratas y gatos, encendida con el olor y el color de la sangre. Sadismo que Proust reencuentra cuando revisita, movido por un sabor, la dulce magdalena, la historia de su vida.

Otro de los modos en que Glantz encuentra la relación entre erotismo y política de manera precisa es en la historia de amor de Hiroshima mon amour, creada por Marguerite Duras, historia épica por la tragedia en la que se teje un amor entre una francesa y un japonés en una ciudad en ruinas. ¿Es la ceniza la amada? es el cuerpo o el cuerpo del deseo de la vida perdida, destruida hasta lo inverosímil por una bomba atómica lo que en verdad se exalta 
en las palabras de Emmanuelle Riva, la actriz, en sus palabras de ritmo firme y contrastado, de manera ritual? Son las cenizas las que han puesto una inscripción indeleble en la Historia, afirma Glantz.

Ella (Duras) es la amante, los amantes, su escritura es cuerpo de mujer, el todo y la nada. Más aún, escribir es un texto amnésico engendrado por una voz repetida interminablemente, la voz es dispar con la imagen visual, aunque a veces la acompañe ayudándola a provocar el orgasmo. Para dejarla sola otra vez. Incompleta y espectante a la noche que manifiesta otra vez la totalidad del deseo. Es, en otra vuelta de tuerca, el retorno de Orfeo y Eurídice, la imposibilidad de la mirada de la amada: ella vuelve del infierno, Orfeo sólo puede oírla, ya que la mirada significa la muerte.

Pero si se la mira, esos ojos que buscan un cuerpo que ya no está ahí donde se lo espera, van hacia la historia y van dirigidos a la lejanía atravesando el tiempo y excluyendo al que mira de su propio tiempo.

En el último capítulo de su texto, Glantz retoma, en "La tumba sin sosiego" al gran Paul Celan, quien se suicida en 1987 y lo contrasta con Primo Levi, autor de Los hundidos y los salvados, también suicida, para preguntar, qué es escribir desde la ceniza, cenizas concretas producidas por los nazis, de manera programada y sistemática.

Para Glantz, Levi, constituye el paradigma de lo decible en relación con el exterminio. Junto a Celan, ambos rompen la prohibición del silencio para referirse a Auschwitz. Prohibición levantada por el filósofo Theodor Adorno y que señala que escribir después de Auschwitz es imposible.

Esta pesadilla recurrente, este naufragio que vuelve a suceder de manera terrible se enuncia con la palabra "Wstavac," palabra de Hölderlin, enigma, estertor casi inaudible, susurro de la locura, palabra llave o contraseña, como la palabra hebrea "Shibboleth," tomada de la Biblia, de los Jueces por Celan para nombrar un doble exterminio, el de los republicanos españoles a manos de los franquistas en 1934 y el de los judíos de la tribu de Efraín exterminados por la tribu de Galaad, reconocidos por la palabra contraseña que los identificaba, palabras de locura semejantes a las de Hölderlin en la torre: Pallaksch, Pallaks, con las que concluye un poema de Celan: 


\author{
“Llegó, sí llegó. \\ Un hombre \\ Llegó un hombre al mundo, hoy \\ Con \\ La barba luminosa \\ Del patriarca; podría \\ Si pudiera hablar de ese \\ Él, si pudiera \\ Balbucear y sólo balbucear, \\ Siempre, siempre \\ Más, más \\ (Pallaksch, Pallaksch)"
}

Wstavac significa una orden emitida en un idioma extranjero, a muchos judíos, la orden alemana, desconocida para muchos de ellos, pues, aunque emitida con ferocidad, como aullido, vuelve a ser desconocida, pierde su sentido de voz humana, $\mathrm{Pa}$ llaksch es una voz oída desde otro campo minado, la locura y hay una tercera voz, la de un niño mudo, del que nos habla Lévi, un niño llamado Hurbinek, al que se oye murmurar: mass-kló o masstikló. "No queda nada de él," dice Lévi, en "La tregua," "El testimonia a través de mis palabras, su minúsculo antebrazo, sellado por un tatuaje en su destino de víctima seriada." ${ }^{2}$

Celan, el gran Celan, ha elegido ser testigo y hacer de su poesía la glorificación de la ceniza, transitando desde diferentes lenguas, desde el alemán, hebreo, yiddish, rumano, ruso, ucraniano, inglés y francés. Sin embargo, eligió hacer desde la noche tenebrosa y romántica del alemán materno, la intimidad yiddish y hebrea de Auschwitz para hacer sonar el destino de los judíos, convirtiéndose en uno de los poetas más necesarios de Europa, más que el mismo Rilke a juicio de Glantz, porque: "Nadie/ testimonia por el/ testigo/ Gloria/ de cenizas/ para Ustedes/ las manos/ del triple camino/ alguna vez Póntico/ aquí un/ una gota/Sobre/ la palma de una rama ahogada/ en el fondo/ del juramento petrificado/ murmura." ${ }^{3}$

Traducción y tradición, miles de lenguas se concitan en la fuerza significante del poema, que deja caer lo más intenso de las religiones judía y católica así como el pensamiento filosófico de Nietzsche, Spinoza, Heidegger, las poéticas de Holderlin y su locura y las de los suicidas Mandelstham y Tsvetaia, el clasicismo de Shakespeare y Dickinson, la parquedad y capacidad visiona- 
ria de Kafka. A quién le habla? Se pregunta Glantz. A la nada, tal vez, a nadie, o a Nietzsche, a Heidegger, a quien no conoció, para todos quizás ese signo ceniza de la lengua, anclada, fija en la oscuridad del tiempo.

Tal vez es de los grandes suicidas judíos de quien Glantz evoca aquí: Stefan Zweig, Walter Benjamin, Tadeus Borowski, Primo Levi, de ellos fue Celan, el último en hablar.

A la idea del testigo, el que narra la historia de Primo Levi, seguido por Giorgio Agambem y al concepto de musulmán, el que ha perdido la humanidad y cae en el automatismo y el silencio, a ellos dedica la última parte de su libro Margo Glantz para decirnos que el tatuaje, el desnudo, el corte de la cabellera, son algunos de los signos que cobran espesor en los textos de Levi como estrategias de clasificación y privación, deshumanización, tortura y muerte, estrategias de una retórica de exterminio, en cuyo relato, faltan las voces de las mujeres, porque quizá ellas eran las primeras en morir. La mujer emerge como cuerpo reducido a su esencia, zoé, biología, pura posibilidad reproductiva. Es en esa dirección que debe entenderse la vida humana, una acepción primitiva e insoslayable, como lo ha dejado claro, la biopolítica.

Así cierra Margo Glantz este libro múltiple, con un homenaje a quienes han escrito sobre el genocidio nazi, atravesando la frontera de lo decible como lo ha hecho Paul Celan o convirtiéndose en la angustiada figura que se siente irrevocablemente unido a dar voz y cuerpo a los fantasmas de una historia fatídica como Primo Levi, el testigo que sumergiéndose en el trauma de la repetición incesante, paga con su cuerpo el relato entregado a Europa y al resto de la civilización occidental.

De esta manera, Glantz cierra el libro demostrando que entre vida y texto hay un cuerpo que se construye, gozosa o dolorosamente; hay una problemática histórica y una deuda que el relato cancela o cobra, hay una voz que calló en un momento y que transcrita abre la vía múltiple de un sexo, una pulsión, una pasión desde la que se escuchan los latidos del sexo de mujer, abierto en todas sus dimensiones y huellas de sentidos. 


\section{Notas}

1 Glantz, Margo. La polca de los osos, p. 24. Santiago: Editorial Cuarto Propio, 2008.

2 Glantz, Margo. op. cit. p. 165.

3 Glantz, Margo, op. cit. p. 171-2. 